RESENHAS 



\section{Construindo direitos: os trabalhadores e a Justiça do Trabalho}

\section{Rinaldo José Varussa*}

SOUZA, Edinaldo Antonio Oliveira. Lei e costume. Experiências de trabalhadores na Justiça do Trabalho. Salvador: Edufba, 2012.195 p.

Palavras-chave: Legislação e Justiça do Trabalho; Experiências de trabalhadores; Recôncavo baiano (Brasil).

Keywords: Legislation and Labor Justice; Experiences of workers; Recôncavo baiano (Brazil).

Septuagenária. Quem diria? De nascimento difícil, com crescimento conturbado, jurada de morte inúmeras vezes, juntamente com a suposta era que a registrou, a Consolidação das Leis do Trabalho (CLT) avançou não só em longevidade, mas em sua abrangência, haja vista a extensão de um conjunto de direitos aos empregados domésticos, promulgada em 2013. Assim, ao contrário do que se atribui aos humanos, com os passar dos anos, parece melhorar sua memória, lembrando-se de trabalhadores outrora esquecidos.

Nesse processo "revitalizador", as lutas empreendidas pelos trabalhadores têm representado um papel decisivo, antes mesmo do nascimento da CLT, sendo que as atuações destes empreenderam-se em diferentes lugares e formas.

Os pesquisadores não têm ignorado tal processo e, notadamente nas últimas décadas, parecem ter engrossado este movimento de luta dos trabalhadores, estabelecendo outros sentidos e significados para os embates vividos por estes a partir da legislação trabalhista, tomando a Justiça do Trabalho como um espaço privilegiado por muitos para constituição e consolidação de direitos.

Assim, também os historiadores têm buscado pesquisar os caminhos percorridos pelos trabalhadores, nas dinâmicas vividas nas disputas judiciais, contrapondo suas interpretações a outras que ou viam a legislação trabalhista como mero exercício unilateral dos ocupantes do poder ao qual se submetiam os trabalhadores, ou firmando uma laudatória, seduzidos por possíveis encantos daquela septuagenária senhora ou de seus supostos idealizadores. Neste exercício, o processo de constituição da legislação trabalhista e a Justiça correlata vêm expressando o conjunto das relações sociais, produzindo-se em contingências específicas e diversas, as quais cumpre investigar.

* Professor associado na Universidade Estadual do Oeste do Paraná (UNIOESTE), atuando nos cursos de graduação e mestrado em História; vinculado ao Laboratório de Pesquisa "Trabalho e Movimentos Sociais". Email:angri46@gmail.com. 
É nessa perspectiva que "Lei e costume" de Edinaldo Antonio Oliveira Souza vêm contribuir, ao propor a discussão sobre "as experiências de trabalhadores na Justiça do Trabalho" (subtítulo do livro) no Recôncavo Baiano. Ou, nas palavras do autor, trata-se de entender "os trabalhadores, ao recepcionarem os discursos e propostas do projeto trabalhista", realizando "desvios, apropriações, re-significações dos seus [dos legisladores] propósitos", já que aqueles eram sujeitos também e "não papéis em branco esperando para ser grafados" (pp. 43-44).

A partir de uma pesquisa de mestrado desenvolvida no Programa de Pós-Graduação em História da Universidade Federal da Bahia, o sentido de contribuição deste trabalho ressalta-se de imediato na delimitação firmada pelo autor a sua pesquisa: trata-se de pensar a Justiça do Trabalho a partir de uma região e num espaço institucional - a Justiça Comum (especificamente, as das Comarcas de Cachoeira, Nazaré e Santo Antonio de Jesus) e não as Juntas de Conciliação e Julgamento -, lugares e situações ainda pouco investigados no que se refere à temática.

Neste universo de relações, o trabalho amplia o leque de contribuições, à medida que categorias profissionais pouco estudadas e mesmo inexistentes em outras regiões do Brasil - tais como a dos que labutam na produção fumageira -, outras que supostamente não seriam abarcadas pela legislação trabalhista - como os trabalhadores rurais e domésticos -, em situações específicas - analfabetos (aproximadamente um terço dos proponentes dos processos analisados), negros, mulheres e predominantemente não sindicalizados -, muitos abarcando todas estas características, evidenciando suas lutas a partir da Justiça do Trabalho. Aliás, nesta caracterização dos trabalhadores, trabalhada principalmente no primeiro capítulo, o autor lança mão de uma tentativa de síntese baseada na construção de estatísticas a partir dos processos trabalhistas investigados, que, curiosamente, ao invés de uma homogeneização da realidade o que emerge é uma diversidade de situações vividas pelos trabalhadores.

Na empreitada de entender as formas como os trabalhadores pautaram suas lutas, um dos temas destacados por Oliveira Souza e que perpassa a totalidade do livro, embora destacado no terceiro capítulo, é o da conciliação. Esta forma de resolução das disputas na Justiça do Trabalho é sublinhada por parte da bibliografia como principal objetivo da instituição, baseando-se nas intenções, definições produzidas pelos idealizadores da legislação trabalhista e repetida pelos integrantes da instituição, como o faz o juiz Germano Monteiro dos Santos, citado no livro: "a finalidade da legislação trabalhista é conciliar empregadores e empregados e não incentivar discórdias” (p.115). Pode até ser que esta seja a intenção. Mas, esta assume um significado em "Lei e costume" que engrossa o coro de uma contraposição constituída, nas últimas décadas, entre os historiadores principalmente: ainda que majoritariamente ponha termo às disputas - nesta pesquisa, próxima à metade dos processos em que houve conclusão -, a conciliação não é sinônimo de uma harmonização das relações de trabalho. Como fica evidenciado no trabalho de Oliveira Souza, encerrar uma ação trabalhista nestes termos consubstanciava um conjunto de práticas e avaliações dos trabalhadores indicativas e explicitadoras de conflitos, disputas, tensões, perdas e ganhos. Afinal, como lembra Edinaldo Souza, para os trabalhadores, acionar a Justiça, é classicamente definido como "colocar no pau".

Um segundo tema importante presente em "Lei e costume" e que parece referendar o seu título é a permeabilidade da lei às tradições tidas e construídas no dia-a-dia da produção, na interação entre patrões e empregados. Neste ponto, novamente dialogando com a produção historiográfica, notadamente com E.P. 
Thompson, Oliveira Souza destaca que as "brechas" suscitadas pela legislação, eram explicitadas e alargadas por trabalhadores e seus advogados, os quais traduziam em formulações jurídicas suas experiências, firmando-lhes o caráter de rotinas, situações regulares e constantes, premissas do que seria visto como direito.

Um caso emblemático nesta relação entre os costumes e a legislação, Edinaldo Souza discute a partir do processo instaurado na Comarca de Nazaré por um conjunto de 86 trabalhadores contra a Companhia Hidro-Elétrica Fabril, em 1946. Estes trabalhadores reivindicavam o pagamento de uma gratificação, correspondente a um mês de salário - uma espécie de "preliminar" do $13^{\circ}$. salário, o qual só seria instituído em 1962 -, que não havia ocorrido no ano anterior (1945). Este bônus, alegavam os trabalhadores, "era hábito da empresa" faze-lo "em ocasiões dos festejos juninos e das festividades de fim de ano" (p.160).

A empresa, por sua vez, rebatia a demanda com o argumento de que se tratava de um gesto de generosidade, "meras liberalidades" e "presentes", condenando a ingratidão dos trabalhadores, já que estes se voltavam "contra o ânimo liberal que os deu para querer obrigá-lo, a fina força, a reconhecer essa liberalidade como dever" (p.161).

A ação ganha pelos trabalhadores, sentenciada definitivamente em 1950 pelo TRT-5, após os recursos da empresa, e paga em 1952, baseou-se no reconhecimento por parte da Justiça de que gratificações habitual e continuamente efetuadas, ainda que não formalizadas, perfazem o salário, "enquadrando-se como um ajuste tácito do contrato de trabalho" (p.171).

Como argutamente aponta Oliveira Souza, no processo em questão, expressava-se um flagrante “de conflito entre a visão dos 'de baixo' e a visão dos 'de cima' em torno dos significados cultivados no interior de uma relação paternalista” (p.170), desta feita colocando em cheque a sua eficácia e uma leitura de exercício unilateral do poder. Os trabalhadores aqui tomavam a intenção e o gesto patronal e os invertiam em favor deles e na contraposição a este último, a partir de uma releitura das suas experiências e de seus referenciais, os quais incluíam a legislação.

No que se refere ao trabalho com as fontes, chama a atenção que a fragmentação das evidências, resultado de anos de descaso com as documentações produzidas em diferentes instituições, avalio, impediu o autor de avançar em alguns pontos, como, por exemplo, o das divergências de julgamentos entre as diferentes instâncias da Justiça, para o que, talvez, contribuiria o estabelecimento das trajetórias dos advogados e juízes, um campo em relação ao qual, me parece, o conjunto da produção sobre as disputas na Justiça carece de aprofundamento.

Uma possibilidade em relação a isso vem sendo constituída pelos pesquisadores através da História Oral'. No entanto, este seria um dos limites do trabalho de Oliveira Souza. Embora tenha realizado algumas entrevistas com trabalhadores que viveram o período pesquisado, o autor aborda-as de forma um tanto quanto sintética e enquanto, na expressão do autor, "informação verbal”, sem outras referências aos entrevistados e ao processo de construção das entrevistas que estabeleça uma historicidade dessas narrativas.

É importante que se frise que este suposto limite não desmerece o conjunto do trabalho, que em relação às fontes ainda lança mão de outras possibilidades,

1 Um importante esforço neste sentido vem sendo constituído pelo Memorial da Justiça do Trabalho no Rio Grande do Sul (TRT da $4^{\text {a }}$.Região) que, em 2010, lançou o primeiro volume de Trajetórias de Juízes, organizado por Ângela de Castro Gomes e Elina Gonçalves Pessanha, reunindo a transcrição de entrevistas realizadas com juízes que atuaram naquele tribunal. 
como, por exemplo, o uso da impressa produzida no período por diversos atores, tais como a militância comunista, contemplando o leitor com a interpretação dos sentidos atribuídos à legislação por estes e de que maneira isto se expressava nas disputas judiciais, fazendo com que o livro, para além do que se apontou sucintamente aqui, agregue positivamente aos esforços das últimas décadas na interpretação da Justiça do Trabalho no Brasil.

Recebido em 16/05/2013

Aprovado em 17/05/2013 